\title{
A data analysis and coordination center for the human microbiome project
}

\author{
Jennifer Wortman ${ }^{1 *}$, Michelle Giglio ${ }^{1}$, Heather Creasy ${ }^{1}$, Amy Chen² ${ }^{2}$ Konstantinos Liolios ${ }^{3}$, Ken Chu², \\ Noam Davidovics ${ }^{1}$, Mark Mazaitis ${ }^{1}$, Todd DeSantis ${ }^{2}$, Navjeet Singh ${ }^{2}$, Joshua Orvis ${ }^{1}$, Jonathan Crabtree ${ }^{1}$, Victor Felix ${ }^{1}$, \\ Catherine Jordan ${ }^{1}$, Anup Mahurkar ${ }^{1}$, Rob Knight ${ }^{4}$, Gary Andersen ${ }^{2}$, Nikos Kyrpides ${ }^{3}$, Victor Markowitz ${ }^{2}$, Owen White
}

From Beyond the Genome: The true gene count, human evolution and disease genomics

Boston, MA, USA. 11-13 October 2010

The Human Microbiome Project (HMP) was launched by the National Institutes of Health (NIH) Roadmap for Medical Research and is designed to fuel research into the microbes that live in the various environments of the human body [1]. A major goal of the HMP is to look for correlations between changes in the microbiome and human health. The HMP will generate unprecedented amounts of sequence, annotation and metadata. The analysis of this data requires the ability to collect, integrate, and standardize information of different types and from different sources.

The HMP Data Analysis and Coordination Center (DACC) is the central repository for all HMP data, providing a specialized data management and analysis infrastructure to support the collection, integration and standardization of HMP data and facilitate research. HMP data sets will include over 1000 reference genomes isolated from the human body, as well as $16 \mathrm{~S}$ ribosomal RNA, and whole metagenome shotgun sequencing of samples collected from multiple body sites and individuals. Successful data integration and standardization will rely on the use of controlled vocabularies, the application of quality control measures, and the development of standard operating procedures. The DACC web portal (http://hmpdacc.org) will provide multiple analysis resources to the research community including data query and visualization, comparative genomics, 16S rRNA analysis, and comparative metagenomic community analysis. Reference genome status and relevant metadata are available through the HMP Project catalog (http://www.hmpdacc.org/project_catalog.html) while annotated HMP reference genomes are

Institute for Genome Sciences, University of Maryland School of Medicine, Baltimore, MD, USA

Full list of author information is available at the end of the article provided as part of IMG/HMP (http://www.hmpdaccresources.org/img_hmp), an HMP specific version of the Integrated Microbial Genomes (IMG) data management and analysis system. IMG/HMP serves as a community resource for comparative analysis of HMP genomes in the comprehensive integrated context of all publicly available microbial genomes.

\section{Author details}

'Institute for Genome Sciences, University of Maryland School of Medicine, Baltimore, MD, USA. ${ }^{2}$ Lawrence Berkeley National Laboratory, Berkeley, CA,

USA. ${ }^{3}$ Joint Genome Institute, Walnut Creek, CA, USA. ${ }^{4}$ University of Colorado at Boulder, Boulder, CO, USA.

Published: 11 October 2010

Reference

1. NIH HMP Working Group: The NIH Human Microbiome Project. Genome Res. 2009, 12:2317-2323.

doi:10.1186/gb-2010-11-S1-013

Cite this article as: Wortman et al:: A data analysis and coordination center for the human microbiome project. Genome Biology 2010 11(Suppl 1):013.

Submit your next manuscript to BioMed Central and take full advantage of:

- Convenient online submission

- Thorough peer review

- No space constraints or color figure charges

- Immediate publication on acceptance

- Inclusion in PubMed, CAS, Scopus and Google Scholar

- Research which is freely available for redistribution 